\title{
Correlation of LOX-5 and COX-2 expression with inflammatory pathology and clinical features of adenomyosis
}

\author{
CAIXIA LI $^{1 *}$, RONG CHEN $^{1 *}$, CAIXIA JIANG ${ }^{2}$, LI CHEN $^{3}$ and ZHONGPING CHENG ${ }^{1,4}$ \\ ${ }^{1}$ Department of Gynecology and Obstetrics, Tenth People's Hospital, Tongji University School of Medicine, Shanghai 200072; \\ ${ }^{2}$ Department of Gynecology and Obstetrics, Yangpu Hospital, Tongji University School of Medicine, Shanghai 200090; \\ ${ }^{3}$ Department of Oncology, Shanghai Pudong Hospital, Fudan University, Shanghai 201399; ${ }^{4}$ Department of Gynecological \\ Minimally Invasive Surgery Research Center, Tongji University School of Medicine, Shanghai 200072, P.R. China
}

Received April 21, 2018; Accepted September 20, 2018

DOI: $10.3892 / \mathrm{mmr} .2018 .9618$

\begin{abstract}
Adenomyosis is a common benign disease of women of childbearing age. The typical clinical features are prolonged menstruation, menorrhagia and ingravescent dysmenorrhea. In the present study, the severity of dysmenorrhea was assessed using the visual analogue scale system as follows: 0, No pain; 1-3, minimal pain; 4-6, moderate pain; and 7-10, severe pain. Menstrual blood loss was evaluated using the pictorial blood loss assessment chart (PBAC). Menorrhagia was defined as excessive menstrual blood loss $>80 \mathrm{ml}(\mathrm{PBAC}>100)$ per period. Specimens of eutopic endometrium (EU) and ectopic endometrium (EC) were collected from 20 patients with adenomyosis to evaluate the association between lipoxygenase-5 (LOX-5) and cyclooxygenase 2 (COX-2) and inflammatory pathology and clinical features of adenomyosis. For that purpose, the expression levels of LOX-5, COX-2, interleukin (IL)-6 and IL-8 in the $\mathrm{EU}$ and EC of patients with adenomyosis were determined, and clinical data including dysmenorrhea and menstruation were analyzed. Differences in expression levels of LOX-5 and COX-2 were detected, and the correlations between LOX-5, COX-2, IL-6 and IL-8 in different groups were analyzed. In addition, the correlations between LOX-5, COX-2 and clinical features of adenomyosis were investigated. The present study demonstrated that LOX-5 and COX-2 are overexpressed in EU and EC, and they have positive correlations with IL-6 and IL-8, suggesting that adenomyosis lesions are present in inflammatory pathological conditions. The expression levels of LOX-5 and COX-2 exhibited a correlation with dysmenorrhea and menstruation.
\end{abstract}

Correspondence to: Dr Zhongping Cheng, Department of Gynecology and Obstetrics, Tenth People's Hospital, Tongji University School of Medicine, 301 Yan Chang Road, Shanghai 200072, P.R. China

E-mail: mdcheng18@tongji.edu.cn

*Contributed equally

Key words: lipoxygenase-5, cyclooxygenase 2, adenomyosis, inflammatory pathology, menstruation, dysmenorrhea

\section{Introduction}

Adenomyosis, a common benign disease of women of childbearing age, is caused by the presence of heterotopic endometrial glands and stroma within the myometrium $(1,2)$. The primary clinical manifestations of adenomyosis are prolonged menstruation, menorrhagia and secondary ingravescence dysmenorrhea. It is common to observe increased uterine volume in adenomyosis. A number of patients have high levels of serum CA125. CA125 modified by platelet count and neutrophil-lymphocyte ratio improves the predictive accuracy of adenomyosis-derived pelvic dense adhesion (3). Adenomyosis was considered to be a chronic immune inflammatory disease. Lesions, peripheral blood and/or peritoneal fluid in patients with adenomyosis are rich in a variety of inflammatory immune cells and inflammatory cytokines, and are closely associated with its clinicopathological features (4-7). Guo et al (8) observed that the expression of Toll-like receptor 4 (TLR4) in adenomyosis was increased compared with the normal endometrium. An established cell model revealed that bacterial lipopolysaccharide can promote the inflammatory response and cell proliferation of endometrial stromal cells in adenomyosis, and improved the ability of invasion via the TLR4 signaling pathway. Cyclooxygenase 2 (COX-2) is a key enzyme in the process of synthesis of various endogenous prostaglandins with arachidonic acid. It was called 'stress gene' and can be detected only when its expression is stimulated by inflammatory factors, but not in normal tissue. COX-2 has certain associations with inflammation, cell mitosis and specific signaling transduction pathways. COX-2 regulates the occurrence and development of a wide variety of tumor pathophysiological processes alongside its inflammatory metabolites (9). A previous study demonstrated that targeting the COX-2 gene can significantly inhibit the expression of vascular endothelial growth factor (VEGF) and matrix metalloproteinase-9 in eutopic and ectopic endometrial stromal cells, as well as increase the rate of apoptosis $(10,11)$. Lipoxygenase-5 (LOX-5) is the key enzyme catalyzing the reaction of arachidonic acid to generate leukotrienes. It is present only in a few cell types (including granulocytes, mast cells, dendritic cells and B lymphocytes), and its metabolic products are important inflammatory mediators. A 
preliminary study revealed that LOX-5 was distributed in the cytoplasm and nucleus of the glandular epithelium and mesenchymal cells of endometriosis (12). The expression of prostaglandins and leukotrienes in the peritoneal fluid of patients with endometriosis or adenomyosis is significantly increased compared with normal individuals, and is positively associated with the degree of dysmenorrhea. Non-steroidal anti-inflammatory drugs can effectively relieve the pain (12). Overall, the evidence suggests that LOX-5 and COX-2 may be involved in the inflammatory pathological mechanism of adenomyosis, and may be associated with its clinical features. As a result, the present study aimed to investigate the expression of LOX-5 and COX-2 in eutopic and ectopic endometrium of adenomyosis by reverse transcription-quantitative polymerase chain reaction (RT-qPCR) and western blotting, and analyze its association with interleukin (IL)-6, IL-8 and clinical features of adenomyosis. Understanding the roles of LOX-5 and COX-2 in the inflammatory pathological mechanism of adenomyosis may provide a theoretical basis for anti-inflammatory therapy.

\section{Materials and methods}

Study cohort. A total of 20 patients with uterine adenomyosis who received surgery at the Tenth People's Hospital, Tongji University School of Medicine (Shanghai, China) from April 9, 2015 to July 11, 2016 were included in the present study. The age of the 20 patients with adenomyosis ranged from 32 to 52 years, with a mean of $42.40 \pm 5.37$ years and a mean body mass index (BMI) of $23.12 \pm 2.63 \mathrm{~kg} / \mathrm{m}^{2}$ (range, $18.73-27.73 \mathrm{~kg} / \mathrm{m}^{2}$ ). All cases included were confirmed by postoperative pathology. Reviewed detailed case data included a record of the patients' general information, menstruation history, marital and reproductive history, complications, and clinical symptoms. In total, 20 cases of women who received placing intrauterine device (a type of ring with drugs inserted in the uterine cavity that can replace the contraceptive pill and condoms serving the role of contraception) operation as the control group. little endometrium tissue $\left(0.5 \mathrm{~cm}^{3}\right)$ was scraped about during surgery. All control and adenomyotic women had regular menstrual cycles (28-35 days) and had not received hormonal therapy within the previous 3 months. The exclusion criteria were patients who were diagnosed with tumor, autoimmune or inflammatory diseases. The present study was approved by the Ethics Committee of Tongji University School of Medicine and was performed in accordance with the tenets and guidelines of the Declaration of Helsinki. All patients provided written informed consent.

Specimen collection. The phase of the menstrual cycle was the early proliferative phase. Control endometrium (CE) was obtained from patients who voluntarily had an intrauterine device implanted. Endometrium $\left(0.5 \mathrm{~cm}^{3}\right)$ was collected prior to the operation. Eutopic endometrium (EU) was obtained from patients with adenomyosis. A little endometrium was collected prior to the operation from the normal uterine wall, while ectopic endometrium (EC) was obtained from intraoperative excised specimens. The specimens were stored in liquid nitrogen $\left(-196^{\circ} \mathrm{C}\right)$ for RNA and protein extraction.
$R T-q P C R$. Liquid nitrogen-preserved tissues were homogenized and total RNA was extracted using the TRIzol method (Invitrogen; Thermo Fisher Scientific, Inc., Waltham, MA, USA). Quantscript RT Kit (KR-103, Tiangen Biotech Co., Ltd., Beijing, China) was used to prepare complementary DNA, which was used as template for PCR amplification. The PCR primer sets used are presented in Table I. QuantiFast SYBR Green PCR Kit (cat. no. 204054, Qiagen, Inc., Valencia, CA, USA) was used and $\beta$-actin served as an internal control.

The amplification program was as follows: $95^{\circ} \mathrm{C}$ for $5 \mathrm{~min}$ and 40 cycles of $95^{\circ} \mathrm{C}$ for $15 \mathrm{sec}$ and $62^{\circ} \mathrm{C}$ for $35 \mathrm{sec}$. A melting curve was represented to confirm the specificity of the amplified products. The mRNA expression levels of LOX-5, COX-2, IL- 6 and IL- 8 in CE, EU and EC tissues were detected by RT-qPCR. The $2^{-\Delta \Delta C q}$ method was used to calculate the mRNA levels (13).

Western blotting. Liquid nitrogen-preserved tissues were homogenized and total protein was extracted. Cell lysates buffer (Cell Signaling Technology Inc., Danvers, MA, USA) were added to the tissues collected from all groups, and homogenized for $1 \mathrm{~h}$ at $4^{\circ} \mathrm{C}$. Total protein extracts were quantified by Bicinchoninic acid Protein Assay kit (Thermo Fisher Scientific, Inc.). Proteins ( $20 \mu \mathrm{g})$ were separated by $10 \%$ SDS-PAGE and then transferred to a nitrocellulose membrane. The membranes were blocked with 5\% fat-free dry milk at room temperature for $1 \mathrm{~h}$. The blots were incubated with human anti-COX-2 (cat. no. ab15191, Abcam, Cambridge, UK; 1:1,000), anti-IL-6 (cat. no. ab6672, Abcam, 1:500), anti-IL-8 (cat. no. ab7747, Abcam, 1:500), anti-LOX-5 (cat. no. ab169755, Abcam, 1:1,000) and anti-GAPDH (cat. no. 2118S, Cell Signaling Technology, Inc., Danvers, MA, USA) overnight at $4^{\circ} \mathrm{C}$. The membranes were again washed with PBS and incubated with horseradish peroxidase (HRP)-conjugated goat anti-rabbit IgG secondary antibodies (cat. no. P0448; Dako; Agilent Technologies, Inc., Santa Clara, CA, USA; 1:2,000) at room temperature for $1 \mathrm{~h}$. The proteins were finally examined by an enhanced chemiluminescence system (ECL; Bio-Rad Laboratories, Inc., Hercules, CA, USA). Band intensities were quantified by densitometry using ImageJ Software version 1.6 (National Institutes of Health, Bethesda, MD, USA).

Statistical analysis. All statistical analyses were performed with SPSS version 16.0 for Windows (SPSS Inc., Chicago, IL, USA). Normally distributed data are presented as the mean \pm standard deviation of three independent experiments and intragroup differences were investigated using analysis of variance, followed by the Bonferroni method to correct for errors. Categorical variables were expressed as the number of cases and percentages. Correlations between variables for each group were determined using the Pearson's correlation coefficient. $\mathrm{P}<0.05$ was considered to indicate a statistically significant difference. Statistics diagrams were represented with GraphPad Prism 5 (GraphPad Software, Inc., La Jolla, CA, USA).

\section{Results}

General data of patients. The age of the 20 patients with adenomyosis ranged from 32 to 52 years, with a mean of $42.40 \pm 5.37$ years and a mean body mass index (BMI) 
Table I. Reverse transcription-quantitative polymerase chain reaction primer, annealing temperature and product.

\begin{tabular}{llc}
\hline Name & \multicolumn{1}{c}{ Primer sequence $\left(5^{\prime}-3^{\prime}\right)$} & Annealing temperature $\left({ }^{\circ} \mathrm{C}\right)$ \\
\hline LOX-5 & F: TGGCAGTCACATCTCTTCC & 61 \\
R: GTGTAGAATGGGTCCCTATG & \\
IL-6 & F: TGAAACCCACTCCAAACACA & 61 \\
R: GAGAAGGCTTCCCAGCTTTT & \\
IL-8 & F: AGCCACTCACCTCTTCAGAAC & \\
& R: GCCTCTTTGCTGCTTTCACAC & 60 \\
& F: CAAGAGCCAGGAAGAAAC & \\
& R: TGGTCCACTCTCAATCAC & 60 \\
\hline
\end{tabular}

IL, interleukin; COX, cyclooygenase; LOX, lipoxygenase.
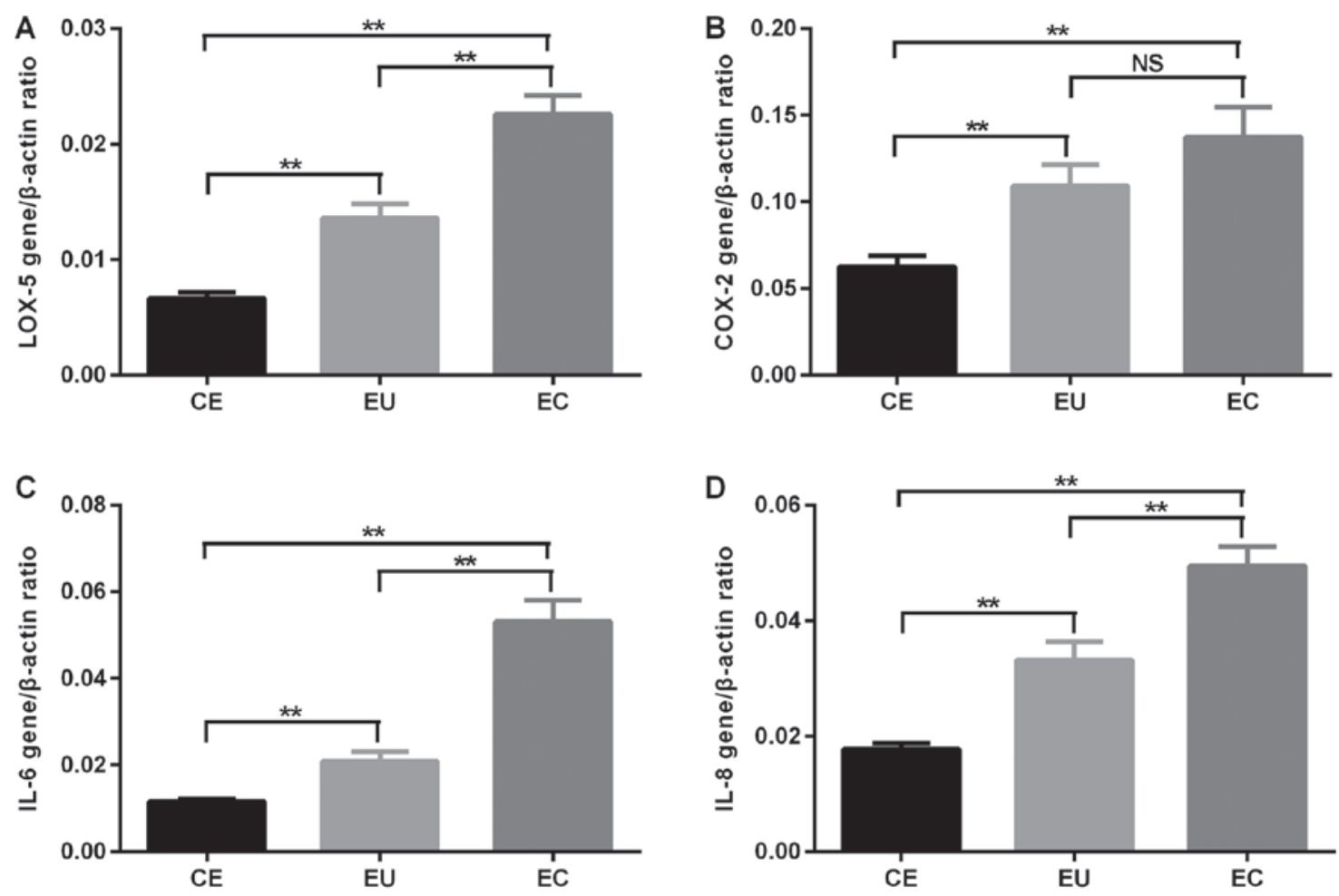

Figure 1. mRNA expression of between (A) LOX-5 and (B) COX 2, (C) IL-6 and (D) IL-8 in the CE, EU and EC. ${ }^{* *}$ P $<0.01$. IL, interleukin; CE, control endometrium; EU, eutopic endometrium; EC, ectopic endometrium; COX-2, cyclooxygenase-2; LOX-5, lipoxygenase-5; NS, non-significant.

of $23.12 \pm 2.63 \mathrm{~kg} / \mathrm{m}^{2}$ (range, $18.73-27.73 \mathrm{~kg} / \mathrm{m}^{2}$ ). The 20 non-adenomyosis subjects were all multiparas who ranged in age from 28 to 46 years, with a mean of $39.46 \pm 7.13$ years and a mean BMI of $22.49 \pm 4.01 \mathrm{~kg} / \mathrm{m}^{2}$ (range, $18.49-26.28 \mathrm{~kg} / \mathrm{m}^{2}$ ). There were no statistically significant differences in age or BMI between the groups $(\mathrm{P}>0.05)$. All the patients with adenomyosis were married and 18 of them had a history of childbirth with an average parity of $1.15 \pm 0.59$ children (range, 0-2 children). A total of 16 cases had a history of abortion, with a mean of $1.45 \pm 1.28$ times (range, $0-5$ times). Two cases had internal diseases (one case of high blood pressure and one case of diabetes).

Expression of LOX-5, COX-2, IL-6 and IL-8 mRNA in CE, $E U$ and $E C$. RT-qPCR analysis revealed that the mRNA expression of LOX-5 in EC and EU was significantly increased compared with in $\mathrm{CE}$, and its expression in EC was significantly increased compared with in EU $(\mathrm{P}<0.01)$. The mRNA expression of COX-2 in EC and EU was significantly increased compared with in $\mathrm{CE}(\mathrm{P}<0.01)$, and there was no significant difference in COX-2 mRNA expression levels between EC and EU. The mRNA expression of IL- 6 and IL- 8 in EC and EU was significantly increased compared with in CE, and it was significantly increased in EC compared with that in EU $(\mathrm{P}<0.01$; Fig. 1 and Table II).

Protein expression levels of LOX-5 and COX-2 in CE, EU and $E C$. Western blot analysis was performed to detect the protein expression of LOX-5 and COX-2 in CE, EU and EC. All 20 adenomyosis patients and 20 non-adenomyosis 
Table II. The mRNA expression of LOX-5, COX-2, IL-6 and IL-8 in CE, EU and EC.

\begin{tabular}{llllrr}
\hline & CE (mRNA) & EU (mRNA) & EC (mRNA) & P $^{\mathrm{a}}$ & $\mathrm{P}^{\mathrm{b}}$ \\
\hline LOX-5 & $0.007 \pm 0.003$ & $0.014 \pm 0.005$ & $0.023 \pm 0.007$ & $<0.01$ & $<0.01$ \\
COX-2 & $0.063 \pm 0.029$ & $0.109 \pm 0.056$ & $0.137 \pm 0.077$ & $<0.01$ & $<0.01$ \\
IL-6 & $0.012 \pm 0.003$ & $0.021 \pm 0.010$ & $0.053 \pm 0.023$ & $<0.01$ & $<0.01$ \\
IL-8 & $0.018 \pm 0.004$ & $0.033 \pm 0.014$ & $0.049 \pm 0.015$ & $<0.01$ & $<0.01$ \\
\hline
\end{tabular}

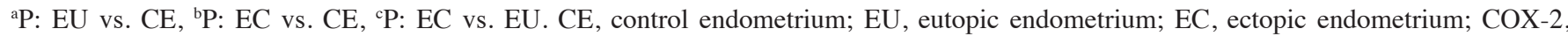
cyclooxygenase-2; LOX-5, lipoxygenase-5; IL, interleukin.
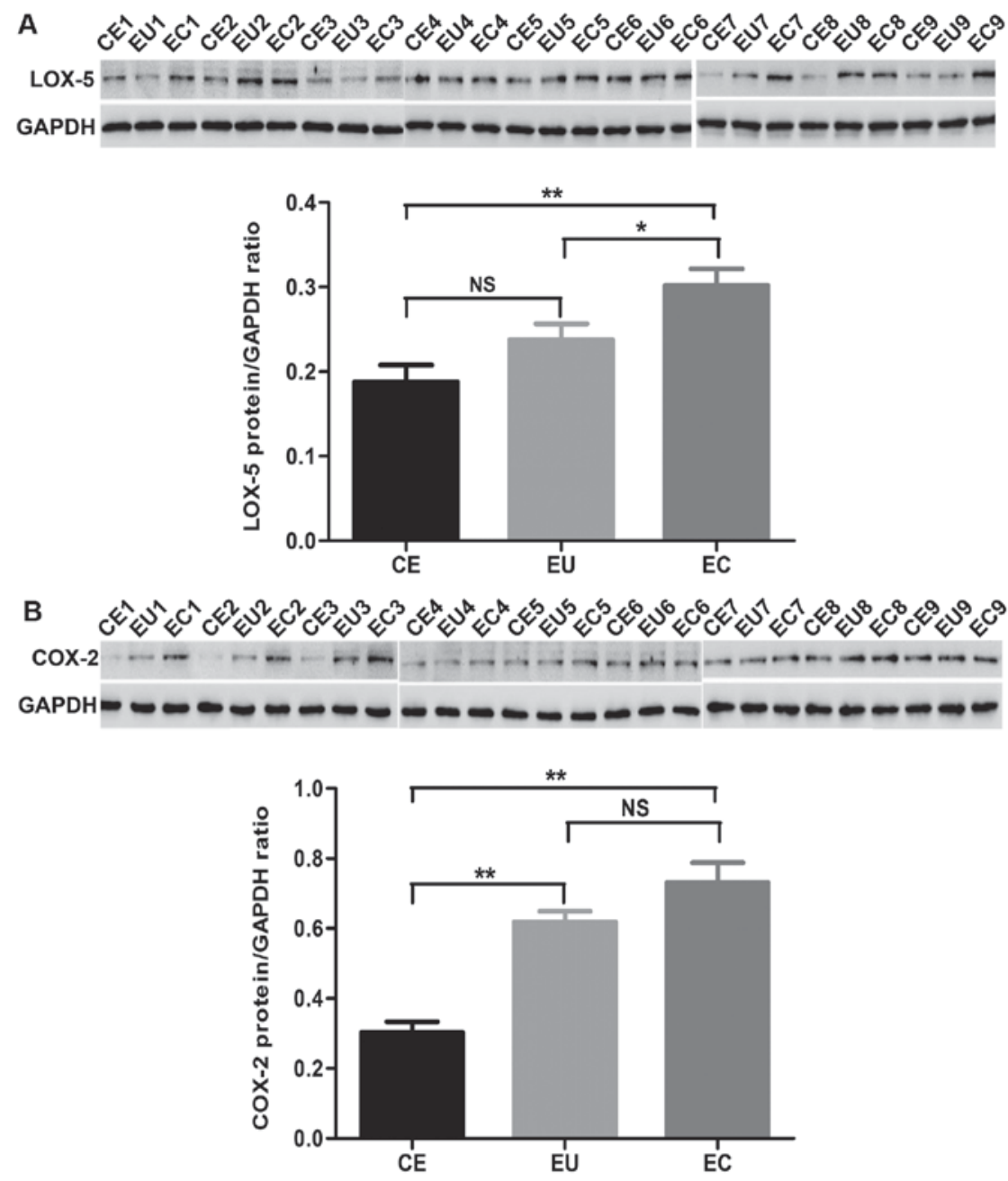

Figure 2. Protein expression of (A) LOX-5 and (B) COX 2 in CE, EU and EC. "P $<0.05,{ }^{* * *} \mathrm{P}<0.01$. CE, control endometrium; EU, eutopic endometrium; EC, ectopic endometrium; COX-2, cyclooxygenase-2; LOX-5, lipoxygenase-5; NS, non-significant.

subjects were tested by western blotting. In this study, 9 samples were chosen as typical as demonstrated in Fig. 2. The total results are presented as a histogram. The protein expression level of LOX-5 in EC was significantly increased compared with in $\mathrm{CE}$ and $\mathrm{EU}(\mathrm{P}<0.01$ and $\mathrm{P}<0.05$, respectively), and there was no significant difference between $\mathrm{CE}$ and EU. The protein expression level of COX-2 in EC and EU was significantly increased compared with $\mathrm{CE}(\mathrm{P}<0.01)$, and there was no significant difference between $\mathrm{CE}$ and $\mathrm{EU}$ (Fig. 2 and Table III).
Correlations between the mRNA expression levels of LOX-5 and COX-2 with IL- 6 and IL-8 in CE, EU and EC. There was a significant positive correlation between the mRNA expression levels of LOX-5 and COX-2 and the levels of IL-6 and IL- 8 in $\mathrm{CE}(\mathrm{P}<0.05)$, and the mRNA expression levels of LOX-5 and COX-2 were also positively correlated with those of IL- 6 and IL- 8 in EU $(\mathrm{P}<0.01)$. There was also a significant positive correlation between the mRNA expression levels of LOX-5 and COX-2 and the levels of IL- 6 and IL- 8 in EC $(\mathrm{P}<0.01$ and $\mathrm{P}<0.05$, respectively; 
Table III. The protein expression of LOX-5 and COX-2 in CE, EU, EC.

\begin{tabular}{|c|c|c|c|c|c|c|}
\hline & $\mathrm{CE}$ & $\mathrm{EU}$ & $\mathrm{EC}$ & $\mathrm{P}^{\mathrm{a}}$ & $\mathrm{P}^{\mathrm{b}}$ & $\mathrm{P}^{\mathrm{c}}$ \\
\hline LOX-5 & $0.192 \pm 0.088$ & $0.238 \pm 0.081$ & $0.299 \pm 0.089$ & $>0.05$ & $<0.01$ & $<0.05$ \\
\hline COX-2 & $0.303 \pm 0.135$ & $0.619 \pm 0.135$ & $0.731 \pm 0.253$ & $<0.01$ & $<0.01$ & $>0.05$ \\
\hline
\end{tabular}

${ }^{\text {aP: }}$ EU vs. CE, ${ }^{\text {pP: }}$ EC vs. CE, 'P: EC vs. EU. CE, control endometrium; EU, eutopic endometrium; EC, ectopic endometrium; COX-2, cyclooxygenase-2; LOX-5, lipoxygenase-5; NS, non-significant.

Fig. 3). The correlation coefficient (r) values are presented in Table IV.

Clinical features of the adenomyosis group

Menstruation. According to the pictorial blood loss assessment chart the adenomyosis patients were divided into two groups. There were $13(65 \%)$ cases of normal menstrual capacity and $7(35 \%)$ cases of menorrhagia. The mRNA expression levels of COX-2 and LOX-5 in the menorrhagia group were significantly increased compared with in the normal group $(\mathrm{P}<0.01$ and $\mathrm{P}<0.05$, respectively) in $\mathrm{EC}$. The mRNA expression of COX-2 in the group of menorrhagia was increased compared with in the normal group $(\mathrm{P}<0.05)$ in EU, but the mRNA expression of LOX-5 had no significant difference between the two groups (Fig. 4).

Dysmenorrhea. According to the visual analog scale system (12), the patients with adenomyosis were divided into 3 groups. There were $3(15 \%)$ cases of minimal dysmenorrhea, 5 (25\%) cases of moderate dysmenorrhea and $12(60 \%)$ cases of severe dysmenorrhea. There was no difference in the mRNA expression of COX-2 among the three groups in EU. The mRNA expression of LOX-5 in EU in the group of moderate and severe dysmenorrhagia was increased in the minimal group $(\mathrm{P}<0.05)$, but there was no difference between the moderate and severe dysmenorrhagia groups. The mRNA expression of LOX-5 and COX-2 in $\mathrm{EC}$ in the groups of moderate and severe dysmenorrhagia was increased compared with in the minimal group $(\mathrm{P}<0.05)$, but not in the moderate or severe dysmenorrhagia groups (Fig. 5).

\section{Discussion}

Adenomyosis is a chronic immune inflammatory disease. The inflammation microenvironment of local lesion tissue serves an important role in the occurrence and development of endometrium and adenomyosis, and is closely associated with the patients' clinical symptoms (14). In previous years, numerous studies have reported that there is not only a large quantity of inflammatory cell infiltration, but also a variety of inflammatory cytokines in adenomyosis lesions. IL-6 and IL-8, as cytokines, are the most commonly used markers of adenomyosis' inflammation pathological state $(15,16)$. Another report indicated that there was gathered neutrophils (NEU) in the peritoneal fluid and ovary nidus of patients with endometriosis. NEU chemokines (IL-8) and the formation of the neutral extracellular traps when NEU was activated were significantly increased in the peritoneal fluid, which was closely associated with inflammation pathology in endometriosis (17). The
Table IV. Correlations between the mRNA expressions of LOX-5, COX-2 and IL-6, IL-8 in CE, EU and EC.

\begin{tabular}{lcc}
\hline Tissue & IL-6 & IL-8 \\
\hline LOX-5 & & \\
CE & $0.856^{\mathrm{b}}$ & $0.619^{\mathrm{b}}$ \\
EU & $0.923^{\mathrm{b}}$ & $0.940^{\mathrm{b}}$ \\
EC & $0.509^{\mathrm{a}}$ & $0.578^{\mathrm{b}}$ \\
CE & $0.861^{\mathrm{b}}$ & $0.821^{\mathrm{b}}$ \\
COX-2 & & \\
EU & $0.889^{\mathrm{b}}$ & $0.847^{\mathrm{b}}$ \\
EC & $0.890^{\mathrm{b}}$ & $0.890^{\mathrm{b}}$ \\
\hline
\end{tabular}

${ }^{\mathrm{a}} \mathrm{P}<0.05,{ }^{\mathrm{b}} \mathrm{P}<0.01$. EU, eutopic endometrium; $\mathrm{CE}$, control endometrium; EC, ectopic endometrium; COX-2, cyclooxygenase-2; LOX-5, lipoxygenase-5.

present study indicated that the mRNA expression of IL-6 and IL-8 in EC and EU was increased compared with in CE in patients with adenomyosis, which was in accordance with the majority of previous studies, and also verified the inflammatory pathological state of adenomyosis.

As two key enzymes in the arachidonic acid (AA) metabolic pathways, LOX-5, COX2 and their metabolic products (prostaglandin E2 and leukotriene B4) not only are involved in the regulation of pathophysiological processes but are also associated with the occurrence and development of a wide variety of tumors. The present study demonstrated that the COX-2 gene and protein expression levels in cervical squamous cell carcinoma and adenocarcinoma tissues were significantly higher than those in normal cervical tissues (18). The expression of COX-2 in ovarian cancer cells was also significantly higher than that in benign ovarian cystadenoma cells (19). Fujiwaki et al (20) detected the expression of COX-2 and VEGF in 63 patients with endometrial cancer by RT-qPCR and immunohistochemistry, and observed that COX-2 had a significantly positive correlation with VEGF. The above studies suggest that COX-2 may serve a certain role in the occurrence and development of gynecological tumors. Similar to COX-2, LOX-5 also serves an important role in promoting tumor cell proliferation, angiogenesis, invasion and metastasis, and inhibiting tumor cell apoptosis. The present study further detected the expression of COX-2 and LOX-5 in adenomyosis. The results revealed that the mRNA expression levels of LOX-5 and COX-2 in the EC and EU groups were increased compared 

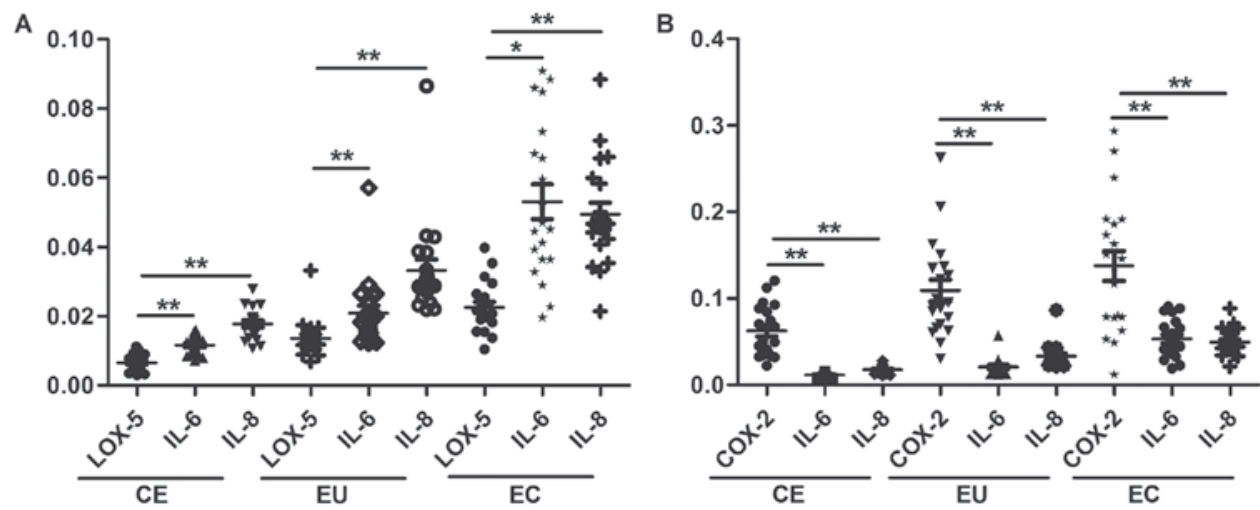

Figure 3. Correlations between the mRNA expression levels of (A) LOX-5 and (B) COX 2, and IL-6 and IL-8 in CE, EU and EC. " $\mathrm{P}<0.05$, ** P $<0.01$. IL, interleukin, CE, control endometrium; EU, eutopic endometrium; EC, ectopic endometrium; COX-2, cyclooxygenase-2; LOX-5, lipoxygenase-5.
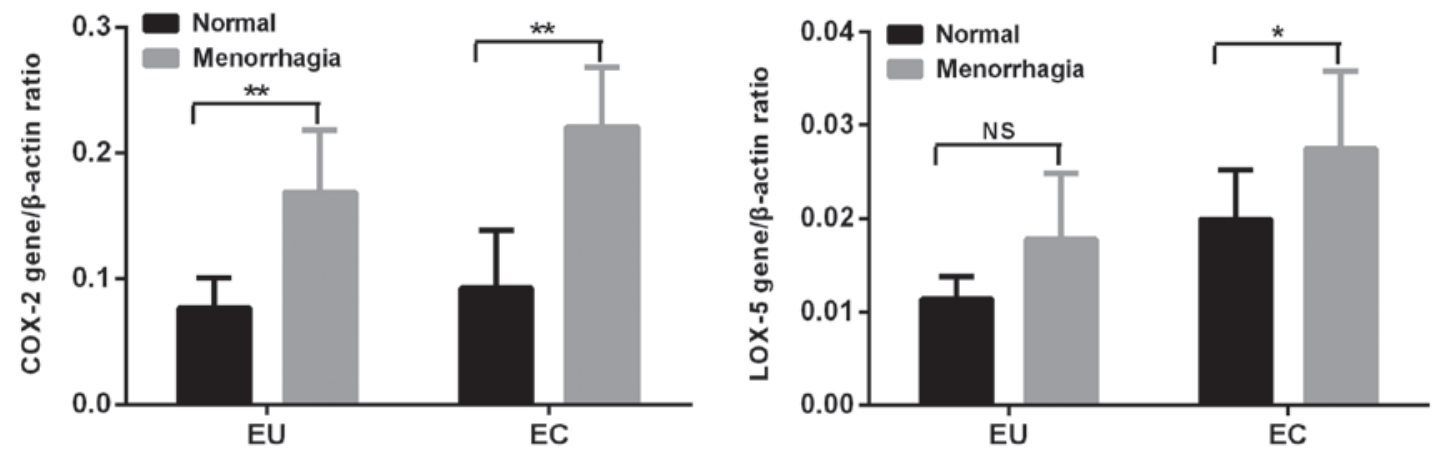

Figure 4. Correlations between the mRNA expression levels of COX-2 and LOX-5 and menstruation in EU and EC. " $\mathrm{P}<0.05$, " $\mathrm{P}<0.01$. EU, eutopic endometrium; EC, ectopic endometrium; COX-2, cyclooxygenase-2; LOX-5, lipoxygenase-5; NS, non-significant.
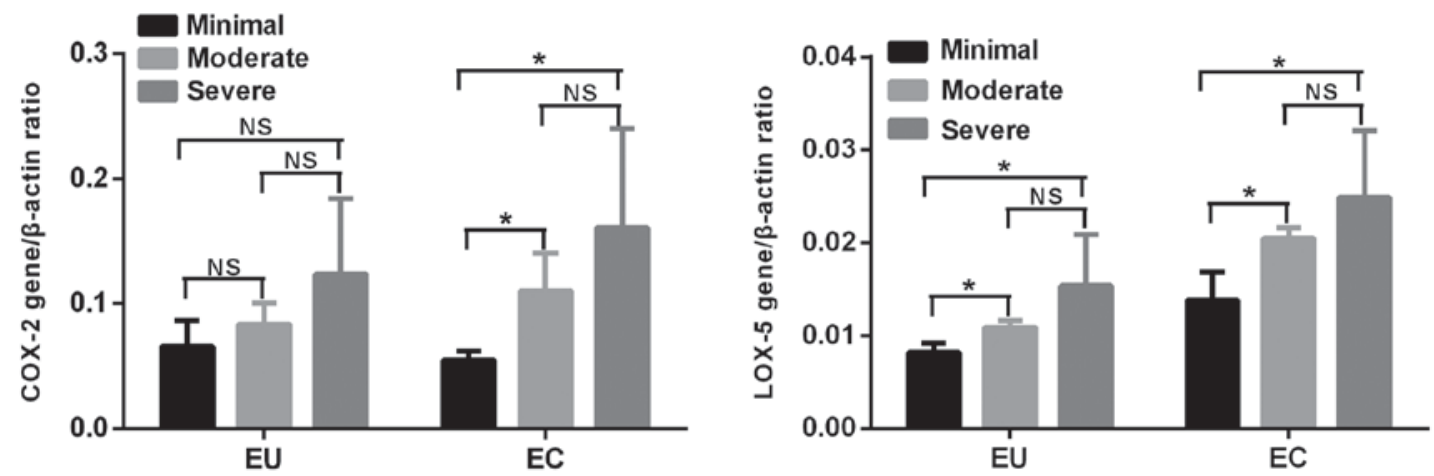

Figure 5. Correlations between the mRNA expression levels of COX-2 and LOX-5 and dysmenorrhea in EU and EC. ${ }^{*} \mathrm{P}<0.05$, ${ }^{\text {*** }} \mathrm{P}<0.01$. EU, eutopic endometrium; EC, ectopic endometrium; COX-2, cyclooxygenase-2; LOX-5, lipoxygenase-5; NS, non-significant.

with in the EC group, and LOX-5 expression in the EC group was higher than in the EU group. Western blotting revealed that the expression of LOX-5 in the EC group was higher than in the $\mathrm{CE}$ and EU groups, while COX-2 expression in the EC and $\mathrm{EU}$ groups was increased compared with in the $\mathrm{CE}$ group. However, the mRNA and protein expression levels of LOX-5 and COX-2 between $\mathrm{CE}$ and EU were slightly different.

There may be several reasons for this result. First, there is a large amount of mRNA to be translated into protein and a certain number of them remain. Next the translation or stability of protein is regulated. Additionally, it was demonstrated that there was no difference in COX-2 expression between the EC and EU groups. In the present study it was hypothesized that this may be ascribed to the small sample size used. Furthermore, COX-2 is an indicator of inflammation; the endometria of the $\mathrm{EC}$ and EU groups are in a state of inflammation, so there is no difference in COX-2 expression between the EC and EU groups. It is known that COX-2 and LOX-5 can create an inflammatory microenvironment and promote the development of cancer by promoting proliferation and angiogenesis while inhibiting tumor cell apoptosis. Accordingly, the present study hypothesized that COX-2 and LOX-5 may be involved in the formation and development of the inflammatory pathology of adenomyosis by regulating the inflammatory pathways. 
Above all, adenomyosis affects women's physical and mental health due to its symptoms including pain and low fertility. The present results revealed that the expression levels of COX-2, LOX-5, IL-6 and IL-8 were increased in normal, EU and EC. In addition, the expression levels of COX-2 and LOX-5 were correlated with the levels of IL- 6 and IL-8, and the expression of COX-2 and LOX-5 was associated with clinical symptoms (i.e., menstrual quantity and/or degree of dysmenorrhea) according to analysis of the clinical data of patients with adenomyosis. These results may provide a theoretical basis for further investigation into the development and progression of the inflammatory pathologies and the underlying immune inflammatory pathogenesis of adenomyosis. Future studies in cell or animal models are required to address the role of COX-2 and LOX-5 in the inflammatory pathogenesis and molecular mechanisms of adenomyosis.

\section{Acknowledgements}

Not applicable.

\section{Funding}

The present study was supported by a grant from the Science and Technology Commission of Shanghai Municipality (grant no. 14411972100).

\section{Availability of data and materials}

All data generated or analyzed during the present study are included in this published article.

\section{Authors' contributions}

CXL wrote the manuscript and performed statistical analysis. $\mathrm{RC}$ contributed to conceptualization. CXJ performed statistical analyses. LC contributed to data curation. ZPC was responsible for the methodology and supervision of the project.

\section{Ethics approval and consent to participate}

The present study was approved by the Institutional Review Board of the Tenth People's Hospital, Tongji University School of Medicine (Shanghai, China). Written informed consent was obtained from all the subjects participating in the study.

\section{Patient consent for publication}

Written informed consent was provided by each patient.

\section{Competing interests}

The authors declare that they have no competing interests.

\section{References}

1. Struble J, Reid S and Bedaiwy MA: Adenomyosis: A clinical review of a challenging gynecologic condition. J Minim Invasive Gynecol 23: 164-185, 2016
2. Benagiano G, Brosens I and Habiba M: Adenomyosis: A life-cycle approach. Reprod Biomed Online 30: 220-232, 2015.

3. Jiang C, Liu C, Guo J, Chen L, Luo N, Qu X, Yang W, Ren Q and Cheng Z: CA125 modified by PLT and NLR improves the predictive accuracy of adenomyosis-derived pelvic dense adhesion. Medicine (Baltimore) 96: e6880, 2017.

4. Khan KN, Kitajima M, Inoue T, Tateishi S, Fujishita A Nakashima $M$ and Masuzaki H: Additive effects of inflammation and stress reaction on Toll-like receptor 4-mediated growth of endometriotic stromal cells. Hum Reprod 28: 2794-2803, 2013.

5. Banu SK, Lee J, Speights VO Jr, Starzinski-Powitz A and Arosh JA: Cyclooxygenase-2 regulates survival, migration, and invasion of human endometriotic cells through multiple mechanisms. Endocrinology 149: 1180-1189, 2008.

6. Nisenblat V, Bossuyt PM, Shaikh R, Farquhar C, Jordan V, Scheffers CS, Mol BW, Johnson N and Hull ML: Blood biomarkers for the non-invasive diagnosis of endometriosis. Cochrane Database Syst Rev: CD012179, 2016.

7. Rižner TL: Diagnostic potential of peritoneal fluid biomarkers of endometriosis. Expert Rev Mol Diagn 15: 557-580, 2015.

8. Guo J, Chen L, Luo N, Li C, Chen R, Qu X, Liu M, Kang L and Cheng Z: LPS/TLR4-mediated stromal cells acquire an invasive phenotype and are implicated in the pathogenesis of adenomyosis. Sci Rep 6: 21416, 2016.

9. Shen J, Li WX, Xiao ZG, Zhang L, Li MX, Li LF, Hu W, Lu L, Boudreau $\mathrm{F}$ and Cho $\mathrm{CH}$ : The Co-regulatory role of 5-lipoxygenase and cyclooxygenase- 2 in the carcinogenesis and their promotion by cigarette smoking in colons. Curr Med Chem 23: 1131-1138, 2016.

10. Lee SJ, Kim CE, Yun MR, Seo KW, Park HM, Yun JW, Shin HK, Bae SS and Kim CD: 4-Hydroxynonenal enhances MMP-9 production in murine macrophages via 5-lipoxygenase-mediated activation of ERK and p38 MAPK. Toxicol Appl Pharmacol 242: 191-198, 2010.

11. Knab LM, Grippo PJ and Bentrem DJ: Involvement of eicosanoids in the pathogenesis of pancreatic cancer: The roles of cyclooxygenase-2 and 5-lipoxygenase. World J Gastroenterol 20: 10729-10739, 2014

12. Lousse JC, Defrère S, Colette S, Van Langendonckt A and Donnez J: Expression of eicosanoid biosynthetic and catabolic enzymes in peritoneal endometriosis. Hum Reprod 25: 734-741, 2010.

13. Livak KJ and Schmittgen TD: Analysis of relative gene expression data using real-time quantitative PCR and the 2(-Delta Delta $\mathrm{C}(\mathrm{T})$ ) method. Methods 25: 402-408, 2001

14. Levy G, Dehaene A, Laurent N, Lernout M, Collinet P, Lucot JP, Lions $\mathrm{C}$ and Poncelet E: An update on adenomyosis. Diagn Interv Imaging 94: 3-25, 2013.

15. Aboussahoud W, Aflatoonian R, Bruce C, Elliott S, Ward J, Newton S, Hombach-Klonisch S, Klonisch T and Fazeli A: Expression and function of Toll-like receptors in human endometrial epithelial cell lines. J Reprod Immunol 84: 41-51, 2010.

16. Khan KN, Fujishita A, Kitajima M, Hiraki K, Nakashima M and Masuzaki H: Occult microscopic endometriosis: Undetectable by laparoscopy in normal peritoneum. Hum Reprod 29: 462-472, 2014.

17. Berkes E, Oehmke F, Tinneberg HR, Preissner KT and Saffarzadeh M: Association of neutrophil extracellular traps with endometriosis-related chronic inflammation. Eur J Obstet Gynecol Reprod Biol 183: 193-200, 2014.

18. Marutha Muthu AK, Cheah PL, Koh CC, Chew MF, Toh YF and Looi LM: Cyclooxygenase-2 (COX2) expression in adenocarcinoma surpasses that of squamous cell carcinoma in the uterine cervix. Malays J Pathol 39: 251-255, 2017.

19. Masferrer JL, Leahy KM, Koki AT, Zweifel BS, Settle SL, Woerner BM, Edwards DA, Flickinger AG, Moore RJ and Seibert K: Antiangiogenic and antitumor activities of cyclooxygenase-2 inhibitors. Cancer Res 60: 1306-1311, 2000.

20. Fujiwaki R, Iida K, Kanasaki H, Ozaki T, Hata K and Miyazaki K: Cyclooxygenase-2 expression in endometrial cancer: Correlation with microvessel count and expression of vascular endothelial growth factor and thymidine phosphorylase. Hum Pathol 33: 213-219, 2002. 